\title{
Efeitos do treinamento físico de alta intensidade sobre os leucócitos de ratos diabéticos
}

\author{
Camila Aparecida Machado de Oliveira, Gustavo Puggina Rogatto e Eliete Luciano \\ Universidade Estadual Paulista-Unesp - Departamento de Educação Física - Rio Claro, SP
}

\section{RESUMO}

Estudos têm demonstrado que o exercício físico regular melhora as condições do diabetes, facilitando a captação periférica da glicose e o metabolismo de glicogênio, proteínas, etc. Por outro lado, pouco se conhece sobre os efeitos do exercício intenso em diabéticos, principalmente com relação ao sistema imune desses organismos. O presente estudo teve como objetivo verificar os efeitos de um treinamento físico de alta intensidade sobre a contagem total e diferencial de leucócitos em ratos diabéticos. Ratos machos jovens Wistar foram distribuídos em quatro grupos: controle sedentário (CS), controle treinado (CT), diabético sedentário (DS) e diabético treinado (DT). O diabetes foi induzido por aloxana $(35 \mathrm{mg} / \mathrm{kg}$ de peso corporal). Durante seis semanas os animais dos grupos CT e DT realizaram um protocolo de treinamento físico, que consistiu na realização de quatro séries de 10 saltos (intercaladas por um minuto de intervalo) em piscina, com o nível da água correspondendo a $150 \%$ do comprimento corporal e sobrecarga equivalente a $50 \%$ da massa corporal dos animais. Ao final do período experimental, amostras de sangue foram coletadas para a contagem total e diferencial dos leucócitos. Os resultados foram avaliados estatisticamente por ANOVA com um nível de significância de 5\%. A glicemia foi aumentada entre os diabéticos e a insulinemia diminuída. Não foram observadas diferenças significativas na contagem diferencial dos linfócitos, neutrófilos, eosinófilos e contagem total de leucócitos entre os grupos estudados. Houve aumento dos monócitos entre os treinados (CS = $10,0 \pm 4,5, \mathrm{CT}^{*}=25,4 \pm 7,9, \mathrm{DS}=19,75 \pm 7,4, \mathrm{DT}^{*}=25,8$

Recebido em 11/12/01

2ํvㄹõo recebida em 12/6/02

Aceito em 29/6/02

Endereço para correspondência:

Camila Aparecida Machado de Oliveira

Rua Josias Freire Santiago, 113, DER

13870-000 - São João da Boa Vista, SP

E-mail: camilaoliv@zipmail.com.br $\pm 4,4 \%)$. O peso relativo do timo foi reduzido pelo treinamento e pelo diabetes $\left(\mathrm{CS}=125,0 \pm 37,7, \mathrm{CT}^{*}=74,6 \pm 8,2\right.$, $\left.\mathrm{DS}^{*}=47,5 \pm 12,2, \mathrm{DT}^{*}=40,1 \pm 16,9 \mathrm{mg} / 100 \mathrm{~g}\right)$. Esses resultados permitem concluir que o treinamento físico de alta intensidade não alterou o estado geral do diabetes, mas aumentou os monócitos, o que pode representar um efeito positivo sobre a resposta imunológica desses animais.

Palavras-chave: Overtraining. Sistema imunológico. Diabetes mellitus. Treinamento físico intenso.

\section{ABSTRACT \\ Effects of high intensity physical training on the leuko- cytes of diabetic rats}

Several studies have demonstrated that regular physical activity improves diabetes conditions, favoring the peripheral glucose uptake, glycogen and protein metabolism. However, the effects of high intensity physical training on the immune system of diabetic organisms are not totally clear. The aim of this study was to verify the effects of high intensity physical training on the total and differential leukocyte count of diabetic rats. Male young Wistar rats were distributed into four groups: sedentary control (SC), trained control $(T C)$, sedentary diabetic $(S D)$ and trained diabetic (TD). Diabetes was induced by alloxan $(30 \mathrm{mg} / \mathrm{kg}$ body weight i.v.). During six weeks the animals of TC and TD groups followed a high intensity physical training protocol which consisted of four sets of 10 jumps/day (interrupted by one minute of rest interval) in a swimming pool, with the water level corresponding to $150 \%$ of the body length and overload equivalent to $50 \%$ of the body weight. At the end of the experimental period, blood samples were collected for total and differential leukocyte count. The results were analyzed by ANOVA at a significance level of 5\%. Serum glucose was increased in diabetic groups while the insulin level was reduced in these groups. There were no significant differences in lymphocytes, neutrophils, and eosinophils, and in total leukocyte count when the groups were compared. Monocytes count was higher in both 
trained groups $\left(S C=10.0 \pm 4.5, T C^{*}=25.4 \pm 7.9, S D=\right.$ $\left.19.75 \pm 7.4, T D^{*}=25.8 \pm 4.4 \%\right)$. The relative weight of the thymus was reduced by diabetes and training $(S C=125.0$ $\pm 37.7, T C^{*}=74.6 \pm 8.2, S D^{*}=47.5 \pm 12.2, T D^{*}=40.1 \pm$ 16.9). In conclusion, the high intensity physical training protocol did not change the general diabetes conditions, but improved relative monocytes. These results can represent a positive effect on the immune response.

Key words: Overtraining. Immune system. Diabetes mellitus. High intensity physical training.

\section{INTRODUÇÃO}

A prática crônica do exercício físico induz diversas adaptações bioquímicas, principalmente no sistema muscular. $\mathrm{O}$ treinamento aeróbio provoca alterações que favorecem a aerobiose, aumentando tanto o número quanto o tamanho das mitocôndrias. Além disso, o exercício físico crônico também resulta em adaptações orgânicas de acordo com as exigências e o tipo de atividade ${ }^{1-3}$.

Quando atletas são submetidos a treinamentos além de suas capacidades, no entanto, alguns sintomas de overtraining, como suscetibilidade à fadiga, distúrbios do sono, perda de peso, dores de cabeça freqüentes, podem aparecer ${ }^{4}$. Estudos mostram ainda que a atividade física pode promover modificações na concentração, na proporção e nas funções das células brancas do sangue, especialmente nos leucócitos polimorfonucleares, nas células matadoras naturais (natural killer), e nos linfócitos, afetando também as imunoglobulinas e outros fatores ${ }^{5}$. Trabalhos citados por Weineck ${ }^{4}$ mostram que, sob estimulação máxima, os hormônios de estresse adrenalina e noradrenalina podem apresentar aumentos de até 10 vezes dos valores basais, por até uma hora depois da atividade; além disso, o cortisol e as catecolaminas não são somente metabólitos ativos, mas também levam a uma redistribuição dos leucócitos, apresentando, desse modo, um efeito imunossupressor ${ }^{6}$.

Além dos hormônios do estresse, a glutamina (aminoácido mais abundante no organismo), cuja maior fonte é o músculo esquelético, é requerida para a proliferação e síntese de nucleotídeo nos linfócitos. A concentração plasmática de glutamina declina agudamente depois de quatro horas de exercício intenso e seu nível durante repouso pode estar baixo em atletas com overtraining, comprometendo a função imune do organismo ${ }^{7}$.

Estudos epidemiológicos recentes, por outro lado, têm proporcionado evidências de que o nível de atividade física está associado com a incidência de diabetes mellitus não insulino-dependente (DMNID), mostrando que um programa de exercício regular pode reduzir o risco de desenvolvimento deste tipo de diabetes ${ }^{8-10}$.
De acordo com Powers e Howley ${ }^{11}$, a prescrição de exercícios para diabéticos tipo II deve ter a freqüência de cinco a sete vezes por semana e intensidade correspondente a $50 \%$ do vंO ${ }_{2}$ máx, a fim de assegurar aumento da sensibilidade à insulina e a perda ou manutenção do peso corporal.

Estudos realizados com animais experimentais também têm demonstrado melhoria do estado geral do diabetes pela realização crônica de exercício físico, principalmente quanto aos aspectos relacionados com o metabolismo de substratos energéticos e as secreções hormonais ${ }^{12-14}$.

Pouco se conhece, entretanto, sobre os efeitos do exercício de alta intensidade em diabéticos, principalmente com relação ao sistema imune desses organismos.

Portanto, o objetivo do presente trabalho foi estudar os efeitos do exercício físico de alta intensidade sobre a contagem total e diferencial de leucócitos em ratos diabéticos.

\section{MATERIAL E MÉTODO}

\section{Animais}

Para o desenvolvimento deste trabalho, foram utilizados 20 ratos machos, adultos jovens, da linhagem Wistar. Os animais eram provenientes do Biotério Central da UnespBotucatu e foram mantidos no Biotério do Departamento de Educação Física - IB - Unesp-Rio Claro. Os animais foram alimentados com ração balanceada padrão para roedores (Purina) e água ad libitum. Os ratos foram mantidos em gaiolas plásticas coletivas (cinco por gaiola) à temperatura ambiente de $25^{\circ} \mathrm{C}$ e fotoperíodo de 12 horas de claro e 12 de escuro.

Para a obtenção do diabetes experimental, os ratos, depois de permanecer 12 horas em jejum, foram anestesiados com éter etílico para receber aloxana monoidratada Sig$m a(35 \mathrm{mg} / \mathrm{kg}$ de peso corporal), dissolvida em tampão citrato $0,01 \mathrm{M}, \mathrm{pH} 4,5$ e injetada na veia peniana dorsal. Posteriormente, os ratos tiveram livre acesso ao alimento e receberam solução glicosada $(30 \%)$ durante 24 horas $^{15}$. A comprovação do diabetes foi realizada 48 horas após a administração de aloxana, através de determinação dos níveis glicêmicos pelo método enzimático colorimétrico da glicose-oxidase (Kit Laborlab).

Os animais foram distribuídos em quatro grupos, da seguinte forma: controle sedentário (CS); controle treinado (CT); diabético sedentário (DS) e diabético treinado (DT).

\section{Treinamento físico}

Após um período de adaptação ao meio líquido (uma hora de natação por dia durante dois dias, sem utilização de sobrecarga), os animais dos grupos CT e DT realizaram um programa de atividade física que consistiu de saltos em tanque com água, com sobrecarga equivalente a $50 \%$ do 
peso corporal de cada animal, acoplada ao tórax. A sessão de treinamento consistiu na realização de quatro séries de 10 saltos com um minuto de intervalo entre as séries. Foram feitas cinco sessões semanais de treinamento durante seis semanas ${ }^{16}$.

A temperatura da água foi mantida entre $30^{\circ} \mathrm{C}$ e $32^{\circ} \mathrm{C}$ por ser considerada termicamente neutra em relação à temperatura corporal do rato ${ }^{17}$.

Os saltos foram realizados em um tubo de PVC com $250 \mathrm{~mm}$ de diâmetro, visando limitar a alternativa do animal em seguir para outra direção, favorecendo dessa forma o salto. O tubo com fundo vazado foi colocado em tanques de amianto com $100 \mathrm{~cm}$ de comprimento, $20 \mathrm{~cm}$ de largura, com água em profundidade correspondente a $150 \%$ do comprimento corporal do rato ${ }^{16,18}$.

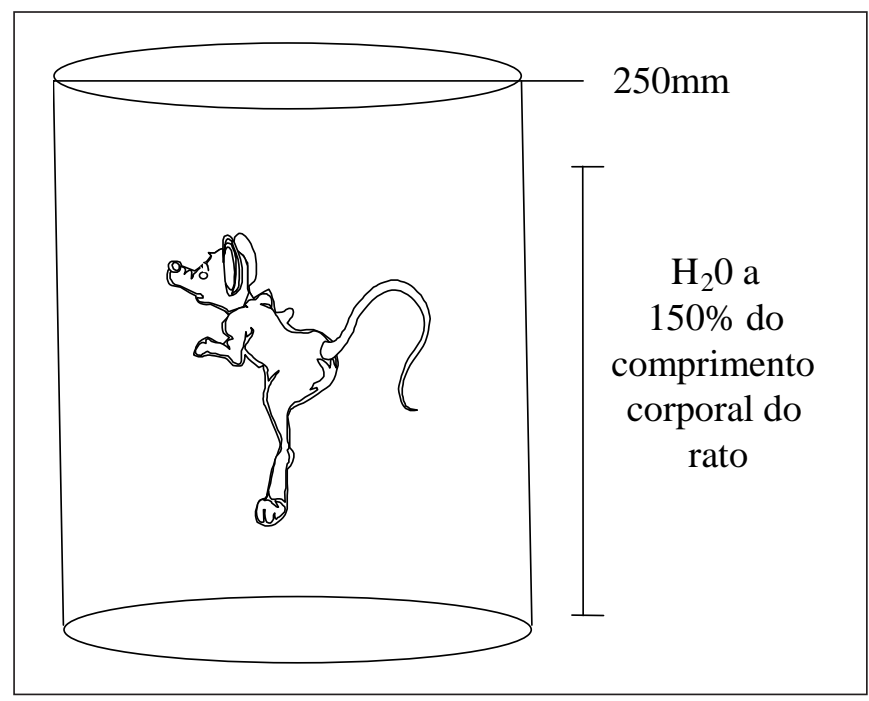

Fig. 1 - Instrumento para a realização de saltos em piscina (reproduzido com autorização de Rogatto GP e Luciano $E^{16}$ ).

\section{Coleta e análise de material biológico}

Ao final do período experimental, foram coletadas duas amostras de sangue da parte distal da cauda de cada rato, sem a utilização de anestesia. A coleta foi feita 24 horas após a última sessão de treinamento. Uma das amostras foi obtida com pipeta específica para glóbulos brancos, completada e diluída em solução de Turk, agitando-se por três minutos. Depois de agitada, a solução foi gotejada na câmara de Neubauer e realizada a contagem total de leucócitos, em microscópio Zeiss ${ }^{19}$.

A outra amostra de sangue foi coletada em uma lâmina de vidro e, posteriormente, feito o esfregaço desta. Despejou-se corante de Leishman, deixando-o reagir sobre a superfície por 15 minutos. Logo em seguida pingaram-se 10 gotas de água destilada sobre a mesma e, após 10 minutos, a lâmina foi lavada com água destilada. O material foi guardado por um dia para a secagem. Depois de secas, as lâminas foram analisadas no microscópio Zeiss, com a utilização de óleo de imersão entre a objetiva e o material observado. Foi realizada a contagem diferencial dos leucócitos utilizando-se um contador mecânico, onde foram registrados os tipos de leucócitos encontrados e posteriormente anotados quando completado o número total de 100 células na lâmina observada ${ }^{19}$.

Os animais foram então sacrificados por decapitação e o sangue foi coletado e centrifugado para determinação da glicemia (método da glicose oxidase) $)^{20}$ e insulinemia por radioimunoensaio (R.I.A.) (Kit Coat-a-Count-DPC, USA). Foi realizada laparotomia mediana para remoção e pesagem do timo.

\section{Análise estatística}

Os resultados foram analisados estatisticamente pela análise de variância (ANOVA two-way) e teste Post Hoc de Bonferroni, com um nível de significância preestabelecido de $5 \%$.

\section{RESULTADOS}

A glicemia dos ratos dos grupos controle e experimental encontra-se representada na tabela 1 . Os resultados indicam aumento significativo $(\mathrm{p}<0,05)$ da glicose sérica entre os grupos DS e DT, caracterizando o diabetes mellitus. Observamos ainda significativa redução $(p<0,05)$ da insulinemia nos grupos DS e DT, o que também confirma o quadro da doença (tabela 1). Não foram observados efeitos decorrentes do esquema de exercício físico proposto sobre esses aspectos.

O peso relativo do timo (PRT) foi menor nos grupos CT, DS e DT, mostrando involução deste órgão entre os grupos experimentais quando comparados com o controle (tabela 1). A análise estatística revelou interação no referido parâmetro.

Os valores obtidos no hematócrito não diferiram entre os grupos experimentais, como mostrado na tabela 1.

Quanto à contagem total de leucócitos, os resultados obtidos não mostram alteração significativa no número destas células (tabela 2).

No que diz respeito à contagem diferencial de leucócitos, não foi verificada diferença significativa entre os grupos para os linfócitos (tabela 2).

Com relação aos monócitos, houve aumento significativo no número destas células nos grupos CT e DT, conforme a tabela 2. A análise estatística mostrou interação nesse subgrupo de leucócitos. 
TABELA 1

Glicemia ( $\mathrm{mg} / \mathrm{dL}$ ), insulina sérica $(\mathrm{mUl} / \mathrm{mL}$ ), peso relativo do timo (PRT) (mg/ 100g) e hematócrito (\%) dos ratos dos grupos CS, CT, DS e DT. Resultados expressos como média \pm desvio padrão

\begin{tabular}{ccccc}
\hline Grupos & Glicose & Insulina & PRT & Hematócrito \\
& & & & \\
CS & $89,9 \pm 5,5$ & $8,2 \pm 2,0$ & $125,0 \pm 37,7$ & $49,5 \pm 2,3$ \\
CT & $86,5 \pm 9,3$ & $7,5 \pm 0,8$ & $74,6 \pm 8,2^{\mathrm{a}}$ & $50,0 \pm 1,5$ \\
DS & $308,2 \pm 33,1^{\mathrm{a}, \mathrm{b}}$ & $4,9 \pm 0,6^{\mathrm{a}, \mathrm{b}}$ & $47,5 \pm 12,2^{\mathrm{a}, \mathrm{b}}$ & $50,5 \pm 1,0$ \\
DT & $343,2 \pm 49,8^{\mathrm{a}, \mathrm{b}}$ & $4,6 \pm 0,3^{\mathrm{a}, \mathrm{b}}$ & $40,1 \pm 16,9^{\mathrm{a}, \mathrm{b}}$ & $49,0 \pm 2,0$ \\
\hline a. $\neq$ CS; b. $\neq$ CT; c. DS $\neq$ DT. & & &
\end{tabular}

TABELA 2

Contagem diferencial de linfócitos, monócitos, neutrófilos e eosinófilos e contagem total de leucócitos ( $\mathrm{n}-$ de células $\times 10^{3}$ por $\mathrm{mm}^{3}$ de sangue). Resultados expressos como média \pm desvio padrão

\begin{tabular}{cccccc}
\hline Grupos & Linfócito & Monócito & Neutrófilo & Eosinófilo & Total \\
CS & $7,0 \pm 2,9$ & $1,6 \pm 0,8$ & $3,3 \pm 1,1$ & $0,24 \pm 0,03$ & $13,2 \pm 0,7$ \\
CT & $6,3 \pm 2,2$ & $4,1 \pm 1,1^{\text {a }}$ & $2,8 \pm 1,1$ & $0,30 \pm 0,05$ & $12,6 \pm 1,5$ \\
DS & $6,7 \pm 2,7$ & $4,1 \pm 1,5$ & $3,9 \pm 0,9$ & $0,22 \pm 0,03$ & $18,8 \pm 2,7$ \\
DT & $5,8 \pm 2,4$ & $4,3 \pm 1,0^{\text {a }}$ & $4,6 \pm 2,0$ & $0,21 \pm 0,02$ & $19,7 \pm 4,5$ \\
\hline a. $\neq$ CS; b. $\neq$ CT; c. DS $\neq$ DT. & & & & \\
\hline
\end{tabular}

Os neutrófilos (tabela 2) não sofreram nenhuma alteração significativa entre os grupos estudados.

Diferença significativa também não foi encontrada entre os grupos na contagem de eosinófilos, como mostrado na tabela 2.

\section{DISCUSSÃO E CONCLUSÃO}

Vários estudos têm demonstrado que o exercício físico regular melhora as condições do diabetes, facilitando a captação periférica da glicose, o metabolismo de glicogênio, proteínas, etc. ${ }^{13,15}$. Pouco se conhece, no entanto, sobre os efeitos do exercício de alta intensidade em diabéticos, principalmente com relação ao sistema imune desses organismos.

De acordo com os resultados obtidos no experimento, observamos que houve aumento significativo $(p<0,05)$ da glicemia nos grupos DS e DT, que, por apresentarem produção diminuída de insulina, conseqüentemente têm prejudicada a captação da glicose pelas células corporais, além de aumento na gliconeogênese, resultando em hiperglicemia. Os resultados mostram também que não houve diferença significativa entre esses grupos (DS e DT). Alguns autores mostram que a atividade física promove aumento na assimilação de glicose e na sensibilidade à insulina pelas célu- las ${ }^{18}$. Entretanto, isso ocorre durante e imediatamente após a realização aguda do exercício. Dessa forma, não se detectou alteração na glicemia, uma vez que o sacrifício ocorreu na condição de repouso.

$\mathrm{Na}$ sequiência dos resultados observamos significativa redução $(\mathrm{p}<0,05)$ da insulinemia nos grupos DS e DT, comprovando o estabelecimento do diabetes mellitus, induzido experimentalmente por ação da droga aloxana, que age destruindo as células $\beta$ das ilhotas de Langerhans do pâncreas, que produzem e secretam a insulina.

Com relação ao peso relativo do timo, os grupos CT, DS e DT apresentaram significativa redução da massa, mostrando maior taxa de involução (tabela 1). Esses resultados corroboram os encontrados na literatura. De acordo com Concordet e Ferry ${ }^{21}$ e Domínguez-Gerpe e Rey-Méndez ${ }^{22}$, o timo responde ao estresse crônico (como o exercício intenso e/ou diabetes) de maneiras diferentes. Involução transitória e perda reversível da massa do timo são freqüentemente observadas. Conforme os referidos pesquisadores, têm sido aceitas algumas hipóteses para explicar tal alteração. A ligação dos glicocorticóides na superfície dos receptores das células do timo pode levar à depleção dos timócitos no córtex. Outros dados sugerem que essa involução possa ser reflexo de uma reduzida migração de células pre- 
cursoras $\mathrm{T}$ da medula óssea para o timo. Esses mesmos autores ainda sugerem uma terceira hipótese para explicar essa involução, relacionada à diminuição da produção e/ ou inativação de quimioatratores do timo ${ }^{22}$. Em nosso trabalho, embora não tenha sido possível realizar medidas específicas para confirmar algumas dessas hipóteses, podemos afirmar que as formas de intervenção utilizadas, diabetes e/ou exercício físico intenso, são capazes de promover a involução do timo.

A elevada taxa de glicose, comum no diabetes mellitus não tratado, pode levar a desidratação das células teciduais, o que pode resultar em aumento relativo da taxa de leucócitos. De acordo com Guyton e Hall ${ }^{23}$, isso ocorre em parte porque a pressão osmótica aumentada nos líquidos extracelulares causa a transferência osmótica da água para fora das células. E além do efeito direto da desidratação celular, a perda de glicose na urina causa diurese osmótica. O efeito global é a grande perda de líquido na urina. Isso então aumenta relativamente o número das células sanguíneas, o que poderia induzir uma leucocitose fisiológica. Em nosso trabalho, tanto o diabetes quanto o treinamento físico não modificaram o número total dessas células. Também não foram verificadas diferenças no hematócrito, o que descarta a possibilidade de ocorrência de desidratação.

Com relação à contagem diferencial de leucócitos, não encontramos diferença significativa no número de linfócitos circulantes entre os grupos estudados. Esse resultado difere dos apresentados na literatura. Conforme Eichner ${ }^{5}$, Nieman $^{6,24}$ e Rowbottom e Green ${ }^{25}$, ocorre linfocitopenia (diminuição do número de leucócitos no sangue), causada pela alta concentração de cortisol, hormônio do crescimento e catecolaminas no plasma. Provavelmente, o fato de não haver diferença nos linfócitos em nosso trabalho esteja relacionado com o protocolo de treinamento físico utilizado, uma vez que a freqüência e intensidade do esforço são aspectos importantes para interferir sobre as subpopulações de leucócitos. O fato de a coleta de sangue ter ocorrido na situação de repouso (cerca de 24 horas após a última sessão de treinamento) pode também explicar esse resultado, uma vez que, segundo Eichner ${ }^{5}$, após este período haveria um retorno dessas células aos níveis basais.

Quanto aos monócitos, foi verificado aumento significativo ( $\mathrm{p}<0,05)$ nos grupos treinados (CT e DT) comparando-se com os outros grupos. Rowbottom e Green ${ }^{25}$ relatam diminuição transitória no número de monócitos circulantes no período pós-exercício. Em nosso trabalho, os ratos encontravam-se em repouso havia 24 horas e, portanto, os efeitos observados foram decorrentes apenas do treinamento e não da sessão aguda de exercício. Considerando que essas células são precursoras dos macrófagos, responsáveis pela fagocitose em determinadas regiões do organismo, esse aumento pode representar uma adaptação importante na defesa do animal treinado.

Quanto à contagem de neutrófilos, não houve diferença significativa entre os grupos estudados. Eichner $^{5}, \mathrm{Nieman}^{6,24}$ e Rowbottom e Green ${ }^{25}$ citam em seus trabalhos uma neutrofilia, causada por ação do aumento no débito cardíaco resultante do efeito da adrenalina. Esses dois aspectos movimentariam os polimorfonucleares (incluindo os neutrófilos) ao longo dos vasos sanguíneos e os liberariam dos pulmões, baço e fígado. O retorno dessas células à linha de defesa leva cerca de 24 horas. É possível que não tenhamos verificado diferenças significativas por causa do repouso de 24 horas, que eliminou a possibilidade de alterações agudas. Outra possibilidade seria a ocorrência de dessensibilização dos adrenoceptores, uma vez que, em estudos citados por Tancréde et al. ${ }^{12}$, ratos cronicamente tratados com adrenalina têm aumentada a sensibilidade à insulina. É importante ainda lembrar que exercícios de força estimulam a secreção de catecolaminas ${ }^{4}$.

Os eosinófilos não apresentaram diferença significativa entre os grupos. Eichner ${ }^{5}$ fala sobre elevação nas células polimorfonucleares, o que inclui os eosinófilos. Os motivos apresentados pelo autor para esse aumento são os mesmos mostrados com relação aos neutrófilos. Isso nos permite reforçar as afirmações anteriores sobre os efeitos agudos e crônicos.

Os resultados obtidos no experimento indicam que o protocolo de treinamento físico intenso não melhorou o estado metabólico geral dos diabéticos, nem modificou o número total ou diferencial da maior parte dos leucócitos. No entanto, a elevação do número de monócitos nos grupos treinados (CT e DT) sugere melhora da resposta imunológica em função do treinamento físico.

\section{REFERÊNCIAS}

1. Snyder AC. Overtraining and glycogen depletion hypothesis. Med Sci Sports Exerc 1998;7:1146-50.

2. Murakami T, Shimomura Y, Fujitsuka N, Sokabe M, Okamura K, Sakamoto S. Enlargement glycogen store in rat liver and muscle by fructosediet intake and exercise training. J Appl Physiol 1997;3:772-5.

3. Kudelska G, Górski J, Swiatecka J, Górska M. Effect of exercise on glycogen metabolism in muscle of triiodotyrosine-treated rats. Eur J Appl Physiol 1996;72:496-501.

4. Weineck J. Treinamento ideal: instruções técnicas sobre o desempenho fisiológico, incluindo considerações específicas de treinamento infantil e juvenil. 9aㅡ ed. São Paulo: Manole, 1999.

5. Eichner ER. Contagious infections in competitive sports. Sports Science Exchange 1995;3:1-4.

6. Nieman DC. Immunity in athletes: current issues. Sports Science Exchange 1998;2:1-11.

7. Mackinnon LT. Chronic exercise training effects on immune function. Med Sci Sports Exerc 2000;7:S369-76. 
8. Manson JE, Rimm EB, Stampfer MJ, Colditz GA, Willet, WC, Krolewski AS. Physical activity and incidence of non-insulin dependent diabetes mellitus in women. Lancet 1991;338:774-8.

9. Kelley DE, Goodpaster BH. Effects of physical activity on insulin action and glucose tolerance in obesity. Med Sci Sports Exerc 1999;11: S619-23.

10. Borghouts LB, Keizer HA. Exercise and insulin sensitivity: a review. Int J Sports Med 2000;21:1-12.

11. Powers SK, Howley ET. Fisiologia do exercício: teoria e aplicação ao condicionamento e ao desempenho. 3a ed. São Paulo: Manole, 2000.

12. Tancréde G, Rousseau-Migneron S, Nadeau A. Beneficial effects of physical training in rats with a mild streptozotocin-induced diabetes mellitus. Diabetes 1982;31:406-9.

13. Luciano E. Influência do treinamento físico sobre o metabolismo de carboidrato em ratos diabéticos experimentais [Tese de doutorado]. São Paulo: Universidade de São Paulo, 1991.

14. Luciano E, Carneiro EM, Reis MAB, Peres SB, Velloso LA, Boschero $\mathrm{AC}$, et al. Endurance training modulates early steps of insulin signaling in rat muscle. Med Sci Sports Exerc 1998;30:S24.

15. Luciano E, Mello MAR. Atividade física e metabolismo de proteínas em músculo de ratos diabéticos experimentais. Revista Paulista de Educação Física 1998;1:39-46.

16. Rogatto GP, Luciano E. Efeitos do treinamento físico intenso sobre o metabolismo de carboidratos. Revista Brasileira de Atividade Física e Saúde 2001;2:39-46.
17. Azevedo JRM. Determinação de parâmetros bioquímicos em ratos sedentários e treinados, durante e após o exercício agudo de natação [Tese de Doutorado]. Campinas: Universidade Estadual de Campinas, 1994.

18. Rogatto GP. Efeitos do treinamento físico de alta intensidade sobre parâmetros endócrino-metabólicos relacionados ao estresse [Dissertação de mestrado]. Rio Claro: Universidade Estadual Paulista, 2001.

19. Lima AO, Soares JB, Greco JB, Galizzi J, Cançado JR. Métodos de laboratório aplicados à clínica. 5ae ed. Rio de Janeiro: Guanabara Koogan, 1977.

20. Henry RJ, Cannon DC, Winkelman J. Clinical chemistry, principles and techniques, $2^{\text {nd }}$ ed. New York: Harper and Row Publishers Inc., 1974.

21. Concordet JP, Ferry A. Physiological programmed cell death in thymocytes is induced by physical stress (exercise). Am J Physiol 1993;3 (pt 1):C626-9.

22. Dominguez-Gerpe L, Rey-Méndez M. Role of pré-t cells and chemoattractants on stress-associated thymus involution. Scand J Immunol 2000; 52:470-6.

23. Guyton AC, Hall JE. Tratado de fisiologia médica. 9a ed. Rio de Janeiro: Guanabara Koogan, 1997.

24. Nieman DC. Is infection risk linked to exercise workload? Med Sci Sports Exerc 2000;7:S406-11.

25. Rowbottom DG, Green K J. Acute exercise effects on the immune system. Med Sci Sports Exerc 2000;7:S396-405. 